\title{
ANALISIS KEAUSAN BESI COR DENGAN LAPISAN HARDCHROME TANPA PELUMAS MENGGUNAKAN PENGUJIAN PIN-ON-DISC
}

\author{
Feri Adi Prayitno, Imam Syafa'at", Darmanto \\ Jurusan Teknik mesin, Fakultas teknik, Universitas Wahid Hasyim \\ Jl. Menoreh Tengah X / 22, Sampangan, Semarang 50236 \\ *Email: imamsyafaat@unwahas.ac.id
}

\begin{abstract}
Abstrak
Gesekan merupakan faktor penting dalam mekanisme operasi sebagian besar peralatan atau mesin. Akibat gesekan antara komponen maka akan timbul adanya pengikisan permukaan komponen atau sering disebut keausan (wear). Hardchrome plating sering dipakai untuk melapisi peralatan atau komponen mesin industri yang bergerak, karena lapisan hardchrome memiliki kekerasan yang tinggi dan lebih tahan terhadap keausan. Tujuan dari penelitian ini adalah untuk mengetahui nilai keausan permukaan besi cor dengan hardchrome plating. Dua buah spesimen besi cor FCD 50 (disc A) dan FCD 60 (disc B) berbentuk disc diberi perlakuan permukaan hardchrome plating. Kemudian dilakukan pengujian point contact (pin-on-disc) dengan pin identor sesuai standar AISI 52100 berbentuk bola berdiameter 9,5 mm dengan menggunakan pembebanan $10 \mathrm{~N}$ dan $20 \mathrm{~N}$ tanpa pelumas. Dari hasil penelitian nilai volume keausan terbesar yaitu $8,5387 \mathrm{~mm}^{3}$ dan volume keausan terkecil yaitu 0,2083 $\mathrm{mm}^{3}$. Koefisien keausan terbesar yaitu $7,1156 \times 10^{-7} \mathrm{~mm}^{3} / \mathrm{N}$.mm dan koefisien keausan terkecil yaitu 1,48985 $\times 10^{-7} \mathrm{~mm}^{3} / \mathrm{N}$.mm. tinggi keausan menggunakan penurunan metode Archard (1953) didapat tinggi keausan terbesar yaitu 0,071125222 mm, dan tinggi keausan terkecil yaitu 0,004248622 $m m$.
\end{abstract}

Kata kunci : Hardchrome, plating, koefisien, wear.

\section{PENDAHULUAN}

Gesekan merupakan faktor penting dalam mekanisme operasi sebagian besar peralatan atau mesin, Akibat gesekan antar komponen tersebut maka akan timbul adanya pengikisan permukaan komponen atau sering disebut keausan (wear). Keausan (wear) adalah hilangnya materi dari permukaan benda padat sebagai akibat dari gerakan mekanik (Syafa'at, 2008). Keausan yang besar terjadi pada bagian benda yang kekerasannya lebih rendah, sehingga keausan merupakan salah satu faktor yang akan mempengaruhi umur dari suatu peralatan atau komponen mesin.

Pengujian keausan bertujuan untuk mengetahui nilai tinggi (volume) keausan permukaan terhadap tekanan benda (beban). Serta untuk mengetahui laju keausan pada waktu tertentu atau diwaktu yang sudah ditentukan. Keausan secara umum dipelajari dalam ilmu tribologi, pengetahuan ini menyangkut gesekan, pelumasan dan keausan (Zum Gahr, 1987). Pengujian keausan dengan tribometer Pin-on-disc (POD) adalah sejenis alat pengujian keausan yang digunakan untuk mengevaluasi perilaku sliding wear terhadap sepasang bahan yang sejenis maupun tak sejenis. Pengujian keausan pin-on-disc, dengan mengukur lebar keausan disc sebagai parameter awal untuk menentukan volume keausan menggunakan persamaan (1), koefisien keausan menggunakan persamaan (2), dan tinggi keausan dengan persamaan (3), (4), dan (5).

$$
\begin{aligned}
& V=\frac{\pi}{6} \times d \times \frac{W^{3}}{R} \\
& V=k_{D} \times F_{N} \times s \\
& \frac{h^{w}}{s}=k_{D} \cdot P \\
& h=\frac{\left(\frac{1}{2} w\right)^{2}}{2 R} \\
& h=\frac{D}{2}-\frac{1}{2}\left[D^{2}-W^{2}\right]^{1 / 2}
\end{aligned}
$$

Pada persamaan (1) dimana persamaan V adalah volume keausan, $d$ adalah radius jalur pengujian, W adalah lebar data pada keausan track disc, R adalah jari-jari pin (Bayer, 2004). Pada persamaan (2) dan persamaan (3) dimana $\mathrm{K}_{\mathrm{D}}$ adalah koefisien keausan, $\mathrm{s}$ adalah jarak sliding, $F_{N}$ adalah beban pin, $h^{w}$ adalah adalah tinggi keausan, dan $\mathrm{P}$ adalah tekanan kontak (Archard,1953), persamaan (4) dimana h adalah tinggi keausan, $\mathrm{W}$ adalah lebar kontak aus, $\mathrm{R}$ 
adalah jari-jari pin (Muchammad, 2018), dan persamaan (5) Dimana $h$ adalah tinggi keausan, $D$ adalah diameter pin, dan $W$ adalah lebar keausan (Stachowiak, 2000).

Perkembangan tentang penelitian keausan hingga saat ini terus dilakukan. Seperti Darmanto, dkk. (2014) melakukan analisa keausan alumunium menggunakan Tribotester Pin-On-Disc dengan variasi kondisi pelumas. Bahan yang digunakan adalah alumunium dengan variasi pelumas, Pelumas yang digunakan SAE 40, SAE 140, dan kering. Faktor keausan terbesar terjadi pada pengujian tanpa pelumas diikuti dengan pengujian menggunakan pelumas SAE 40 dan pengujian dengan menggunakan pelumas SAE 140.

Muchammad, dkk. (2018) menganalisis keausan besi cor grafit bulat untuk aplikasi cylinder linier menggunakan tribotester pin-ondisk. Penelitian ini bertujuan untuk mengetahui volume dan tinggi keausan yang terjadi pada besi cor FCD 50 (79.5 HRB), FCD 50 (82HRB), dan FCD 60 (86.5 HRB). Analisa perhitungan menggunakan penurunan geometri semata dan menggunakan metode penurunan Archard (1953). Volume keausan dan tinggi keausan yang paling besar terjadi pada besi cor FCD 50 dengan kekerasan 79.5 HRB setelah itu FCD 50 dengan kekerasan 83 HRB dan nilai volume keausan dan tinggi keausan terendah pada FCD 60 dengan kekerasan 86.5 HRB.

Sugiharto (2017) melakukan analisa keausan dengan membandingkan dua buah spesimen yang berbeda. Kedua spesimen tersebut berupa disc FCD 50 dan FCD 60 dengan alur buatan hasil pembubutan knurling DIN 82 melalui pengujian tribometer pin-ondisc tanpa pelumas. Jenis knurling yang dipakai adalah RBL left-hand spiral dengan pitch 0,3 $\mathrm{mm}$. Pin berbentuk bola dengan standar AISI 52100 berdiameter $9,5 \mathrm{~mm}$. Tingkat keausan tertinggi pada disc FCD 50 dengan volume keausan 6,9581 $\mathrm{mm}^{3}$ pada jarak 600m. Dan nilai keausan terendah pada disc FCD 60 dengan volume $0,8742 \mathrm{~mm}^{3}$ pada jarak $200 \mathrm{~m}$. Dari analisa tersebut disimpulkan nilai kekerasan material berpengaruh terhadap volume keausan, koefisien keausan dan tinggi keausan.

Priyono (2018) melakukan analisis keausan besi cor FCD 50 dan FCD 60 dengan melakukan kekasaran buatan ( knurling DIN 82), kemudian diberi electroplating hardchrome untuk mengetahui pengaruh kekasaran setelah pelapisan, kemudian melakukan pengujian keausan menggunakan alat tribometer pin on disc. Perhitungan volume keausan menggunakan metode Archard yang menunjukkan tinggi keausan tertinggi sebesar $0,153 \mathrm{~m}$ dengan jarak $600 \mathrm{~m}$ pada besi cor FCD 60 dan terendah sebesar $0,025 \mathrm{~m}$ dengan jarak $200 \mathrm{~m}$ pada besi cor FCD 50. Nilai volume keausan terbesar pada besi cor FCD 60 yaitu $15,721 \mathrm{~mm}^{3}$ dengan jarak $600 \mathrm{~m}$. Serta volume keausan terendah pada besi cor FCD 50 yaitu $0,741 \mathrm{~mm}^{3}$ dengan jarak $200 \mathrm{~m}$.

Salah satu cara untuk mengurangi tingkat keausan adalah dengan perlakuan permukaan hardchrome plating. Menurut Setyahandana dan Christianto (2017) bahwa proses electroplating menggunakan hardchrome disebut juga hardchrome plating.

Metode pelapisan krom keras (Hardchrome plating) adalah jenis penambahan lapisan permukaan yang berbahan dasar kromium. Penambahan lapisan hardchrome secara umum dilakukan pada alat-alat industri yang bergerak, salah satu aplikasinya adalah top compression ring pada piston. Contoh gambar top compression ring dapat dilihat pada Gambar 1, fungsi dari top compression ring adalah sebagai perapat antara piston dengan dinding silinder supaya tidak terjadi kebocoran gas (campuran udara dan bahan bakar) pada saat melakukan langkah kompresi dan langkah usaha. Tujuan dari penelitian ini adalah untuk mengetahui nilai keausan permukaan besi cor dengan hardchrome plating.

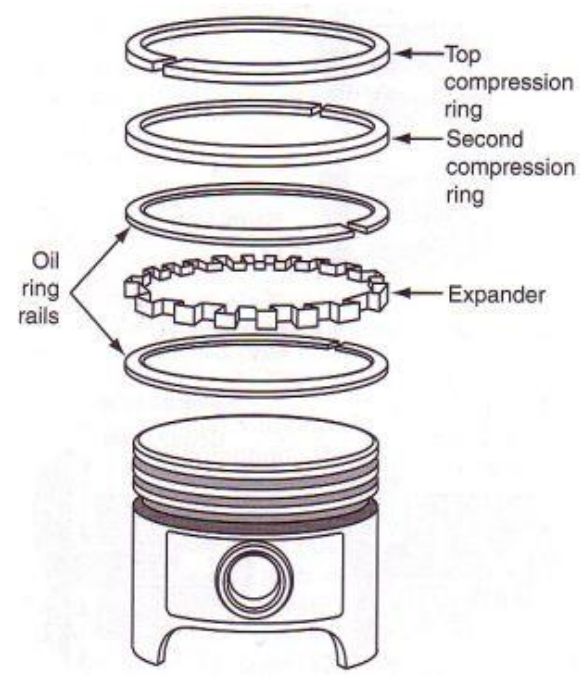

Gambar 1. Fungsi ring piston (Bisa otomotif, 2019) 


\section{METODOLOGI}

Metode yang digunakan dalam penelitian ini adalah dengan cara pengujian keausan menggunakan alat tribometer pin-on-disc pada besi cor FCD 50 dan FCD 60 berbentuk disc yang telah diberi perlakuan permukaan hardchrome plating. Pengujian ini dilakukan pada kondisi kering (dry sliding contact) dengan kecepatan putaran disc diatur menggunakan inverter dengan kecepatan putaran disc $60 \mathrm{rpm}$.

Pin identor dengan standar AISI 52100 berbentuk bola derdiameter $9,5 \mathrm{~mm}$ dan nilai kekerasan pin adalah $60 \mathrm{HRC}$, diberi beban 20 $\mathrm{N}$ dan $10 \mathrm{~N}$ dengan arah penekanan vertikal searah, kontak sliding dengan disc A (FCD 50) dan disc B (FCD 60) yang telah diberi perlakuan permukaan hardchrome plating, menempuh jarak $200 \mathrm{~m}, 300 \mathrm{~m}, 400 \mathrm{~m}, 500 \mathrm{~m}$, dan $600 \mathrm{~m}$. waktu yang ditempuh dengan membandingkan jarak tempuh terhadap kecepatan disc di atas sistem tribologi. Diagram alir pada penelitian ini dapat dilihat pada Gambar 2.

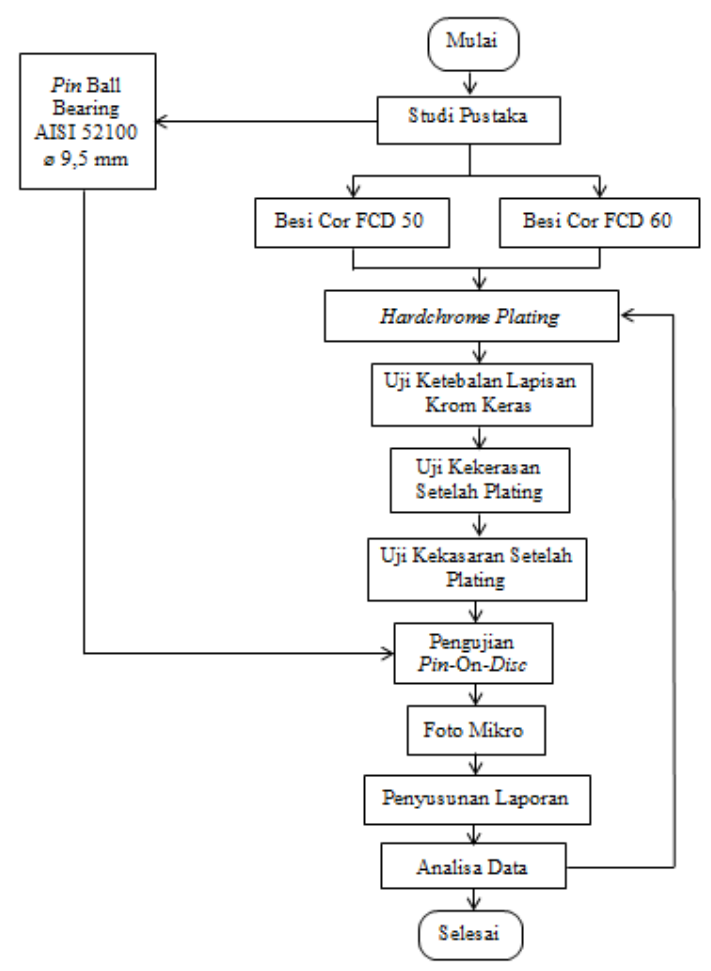

\section{Gambar 2. Diagram alir penelitian}

Penjelasan secara singkat mengenai diagran alir penelitian pada Gambar 2 sebagai berikut :

1. Studi pustaka (literatur)
Studi pustaka dilakukan untuk mengumpulkan data teori, baik dari makalah, jurnal ilmiah, buku, serta laporan pengujian ilmiah lainnya.

2. Menyiapkan bahan eksperimen

Menyiapkan bahan bahan pengujian berupa besi cor FCD 50 dan FCD 60 . Kemudian bahan hardchrome plating (bahan ini berupa bahan kimia dengan berbagai senyawa baik cair maupun padat sebagai larutan pelapisan kimia).

3. Proses elektroplating

Kegiatan ini terdiri dari pengerjaan awal yaitu proses pembesihan spesimen, kemudian proses pelapisan yaitu spesimen dimasukan pada wadah yang berisi cairan elektrolit (kerapatan arus $30 \mathrm{~A} / \mathrm{dm}^{2}$ dan waktu 1 jam). kemudian pengerjaan akhir yaitu pembilasan dan pengeringan setelah elektroplating hardchrome.

4. Uji ketebalan

Kegiatan ini dilakukan untuk mengukur ketebalan lapisan hardchrome pada spesimen dengan alat Coating tickness tester.

5. Uji kekerasan

Kegiatan ini dilakukan dengan alat uji kekerasan vicker untuk menukur kekerasan lapisan permukaan hardchrome spesimen.

6. Uji kekasaran

Kegiatan ini dilakukan dengan alat uji Surface Roughness Tester untuk menukur kekasaran permukaan disc setelah elektroplating hardchrome.

7. Pengujian pin-on-disc (POD)

Pengujian keausan dengan alat tribometer Pin-on-disc (POD) dengan kecepatan putar $60 \mathrm{rpm}$ dengan pembebanan pin $20 \mathrm{~N}$ dan 10 $\mathrm{N}$.

8. Foto mikro

Pengamatan dengan alat Mikroskop metalografi untuk mengukur lebar keausan spesimen setelah pengujian point contact pin-on-disc.

9. Analisa data

Dari hasil pengujian yang didapat, selanjutnya dianalisa menurut studi pustaka. Hasil analisa data ini juga digunakan untuk menyusun laporan.

10.Penyusunan laporan

Bentuk penyusunan laporan dimaksudkan untuk mempertanggung jawabkan semua hasil pengujian yang sudah dilakukan. 


\section{HASIL DAN PEMBAHASAN \\ Data dan Hasil Pengujian Karaktristik Besi Cor FCD 50 dan FCD 60}

Karakteristik besi cor mengalami peningkatan setelah diberi perlakuan permukaan hardchrome plating. Peningkatan karakteristik besi cor dapat dilihat pada Tabel 1 .

Tabel 1. Data disc

\begin{tabular}{|c|c|c|c|}
\hline \multirow{2}{*}{ No } & \multirow{2}{*}{ Disc } & \multicolumn{2}{|c|}{ Nilai } \\
\hline & & Normal & Hardchrome \\
\hline 1 & $\begin{array}{l}\text { Kekasaran disc } \\
\text { A }\end{array}$ & $0.516 \mu \mathrm{m}$ & $0.62 \mu \mathrm{m}$ \\
\hline 2 & $\begin{array}{l}\text { Kekasaran disc } \\
\text { B }\end{array}$ & $0.623 \mu \mathrm{m}$ & $0.786 \mu \mathrm{m}$ \\
\hline 3 & $\begin{array}{l}\text { Kekerasan disc } \\
\text { A }\end{array}$ & $\begin{array}{r}79.5 \\
\text { HRB }\end{array}$ & $714.2 \mathrm{HV}$ \\
\hline 4 & $\begin{array}{l}\text { Kekerasan disc } \\
\text { B } \\
\text { Tebal }\end{array}$ & $\begin{array}{r}86.5 \\
\text { HRB }\end{array}$ & $530.6 \mathrm{HV}$ \\
\hline 6 & $\begin{array}{l}\text { Hardchrome } \\
\text { disc A } \\
\text { Tebal }\end{array}$ & & $10,54 \mu \mathrm{m}$ \\
\hline 7 & $\begin{array}{l}\text { Hardchrome } \\
\text { disc B }\end{array}$ & & $12,8 \mu \mathrm{m}$ \\
\hline
\end{tabular}

Dari Tabel 1 kekerasan disc meningkat hingga 3 kali $(382,3 \%)$ dari kekerasan awal, hal ini sesuai dengan teori bahwa sifat kekerasan lapisan krome memiliki tingkat kekerasan yg tinggi. kakasaran permukaan disc meningkat hingga $26 \%$ dari kekasaran awal, hal ini karena elektroplating adalah proses penambahan zat kimia baru (lapisan) pada permukaan.

\section{Lebar Keausan Disc}

Setelah pengujian keausan menggunakan alat tribometer pin-on-disc, pengukuran lebar keausan pada disc menggunakan alat mikroskop metalografi. Perbandingan nilai lebar keausan pada disc secara grafik dapat dilihat pada Gambar 3. Laju lebar keausan disc B lebih besar dari lebar keausan disc A, hal ini karena permukaan lapisan hardchrome disc A lebih keras dari permukaan hardchrome disc $\mathrm{B}$.

Lebar keausan disc bertambah seiring bertambahnya jarak dan beban yang diberikan. Lebar keausan disc penulis dapat dibandingkan dengan lebar keausan disc Sugiarto (2017) dan Priyono (2018), pada beban pin $10 \mathrm{~N}$ memiliki nilai lebar keausan disc penulis lebih kecil dari nilai lebar keausan disc pada penelitian Sugiharto (2017) dan Priyono (2018). Pada beban $20 \mathrm{~N}$ lebar keausan disc A penulis lebih kecil dari lebar keausan disc Priyono (2018) dan Sugiharto (2017) yang diberi beban $10 \mathrm{~N}$, sedangkan disc $\mathrm{B}$ beban $20 \mathrm{~N}$ penulis lebar keausannya lebih besar dari lebar keausan disc Sugiharto (2017) yang diberi beban $10 \mathrm{~N}$ dan lebih kecil dari lebar keausan disc Priyono (2018) yang diberi beban $10 \mathrm{~N}$.

Hal ini karena pada penelitian Sugiharto (2017) disc diberi kekasaran buatan knurling DIN 82 dan tidak diberi lapisan hardchrome sehingga kekerasan disc lebih lunak dibanding kekerasan disc penulis yang diberi lapisan hardchrome. Sedangkan pada penelitian Priyono (2018) disc diberi kekasaran buatan knurling DIN 82 dan lapisan hardchrome, sehingga permukaan disc lebih kasar dari permukaan disc peneliti, karena lebar keausan disc dipengaruhi oleh lebar keausan pin.

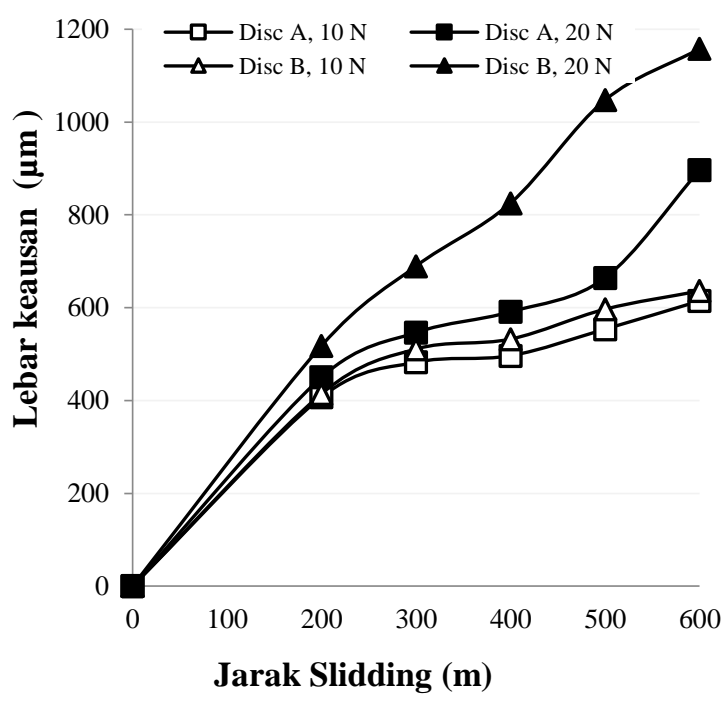

\section{Gambar 3. Grafik perbandingan lebar keausan disc}

\section{Volume Keausan Disc}

Dari Gambar 3 maka dapat dihitung volume keausan disc dengan persamaan 1. Dari hasil perhitungan volume keausan disc secara grafik dapat dilihat pada Gambar 4. Dari Gambar 4 volume keausan terbesar terjadi pada disc $\mathrm{B}$ beban $20 \mathrm{~N}$ jarak $200 \mathrm{~m}$ yaitu 8,5387 $\mathrm{mm}$, dan lebar keausan terkecil terjadi pada disc A beban $10 \mathrm{~N}$ jarak $200 \mathrm{~m}$ yaitu $0,2083 \mathrm{~mm}$.

Volume keausan disc penulis dapat dibandingkan dengan volume keausan disc Sugiarto (2017) dan Priyono (2018). Volume keausan disc A dan disc B beban $10 \mathrm{~N}$ penulis lebih kecil dari volume keausan disc A dan disc B Priyono (2018) dan Sugiharto (2017) yang 
diberi beban $10 \mathrm{~N}$, sedangkan volume keausan disc A beban $20 \mathrm{~N}$ penulis lebih kecil dari volume keausan disc A dan disc B Priyono (2018) dan Sugiharto (2017) beban $10 \mathrm{~N}$. Volume keausan disc B beban $20 \mathrm{~N}$ penulis lebih besar dari volume keausan disc A dan disc B Sugiharto (2017) beban $10 \mathrm{~N}$ dan lebih kecil dari volume keausan disc A dan disc B Priyono (2018) beban $10 \mathrm{~N}$. Hal ini karena pada penelitian Sugiharto (2017) besi cor disc A dan disc B tidak diberi lapisan tetapi diberi kekasaran buatan knurling DIN 82 sehingga kekerasan lapisan hardchrome disc penulis lebih keras dari permukaan besi cor disc A dan disc B Sugiharto (2017) yang tanpa lapisan. Pada penelitian Priyono (2018) besi cor disc A dan disc B diberi kekasaran buatan knurling DIN 82 dan diberi lapisan hardchrome, lebar keausan disc dipengaruhi oleh keausan lebar pin sehingga volume keausan yang terjadi lebih besar dari volume keausan penulis.

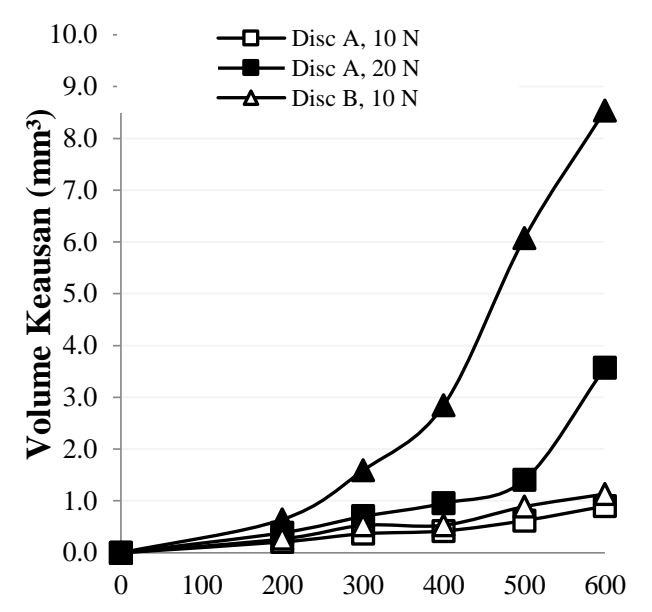

Jarak Sliding (m)

\section{Gambar 4. Grafik perbandingan volume keausan disc}

\section{Koefisien Keausan Disc}

Dari nilai volume keausan disc dengan pembebanan $10 \mathrm{~N}$ dan $20 \mathrm{~N}$, maka dapat dihitung nilai koefisien keausan disc dengan persamaan 2. perbandingan hasil koefisien keausan disc dapat dilihat pada Gambar 5.

Dari Gambar 5 nilai koefisien disc B lebih besar dari koefisien keausan disc A, hal ini karena lapisan hardchrome disc A lebih keras dari disc B. Pada beban $20 \mathrm{~N}$ nilai koefisien keausannya lebih besar dari nilai koefisien keausan beban $10 \mathrm{~N}$, maka dapat disimpulkan semakin besar beban pin yang menekan disc maka koefisien keausannya semakin besar.

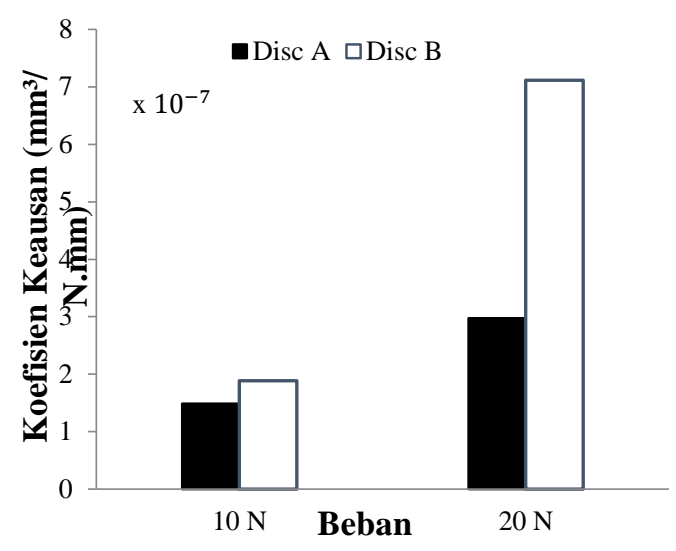

\section{Gambar 5. Perbandingan koefisien keausan disc}

\section{Tinggi Keausan Disc}

Dari nilai koefisien keausan dan volume keausan disc, maka dapat dihitung tinggi keausan disc menggunakan metode Archard (1953) dengan persamaan 3. Tinggi keausan juga dapat dihitung menggunakan metode eksperimen Muchammad (2018) dengan persamaan (4), dan metode Stachowiak (2000) dengan persamaan (5).

Hasil perhitungan tinggi keausan dengan menggunakan metode Archard (1953), metode eksperimen Muchammad (2018), dan metode Stachowiak (2000) dapat dilihat pada Gambar 6.

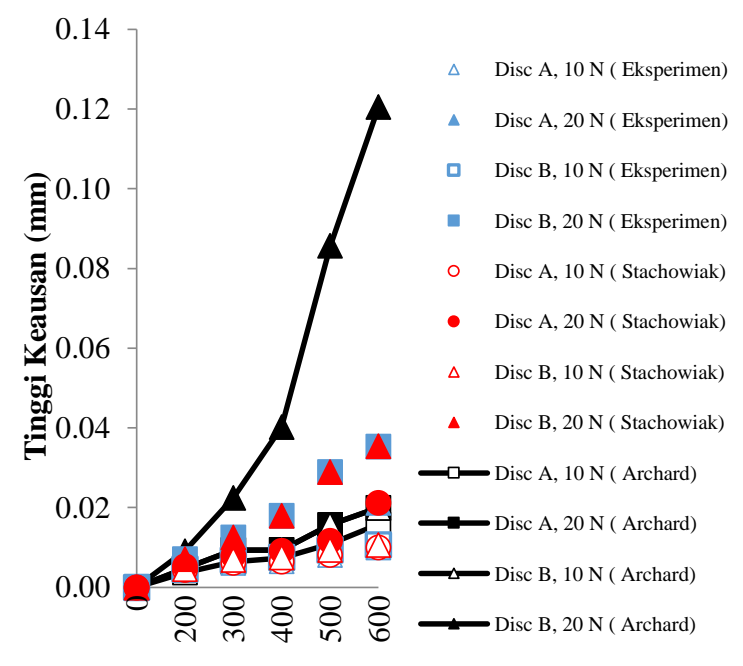

Jarak Sliding (m)

Gambar 6. Hasil perhitungan tinggi keausan

Dari Gambar 6 menunjukan bahwa hasil perhitungan hasil eksperimen dan pehitungan 
menggunakan persamaan Stachowiak memiliki nilai tinggi keausan yang hampir sama hanya berbeda 5 angka dibelakang koma dalam satuan $\mathrm{mm}$. Hasil eksperimen dibandingkan dengan prediksi metode Archard (1953) memiliki prinsip yang sama yaitu semakin jauh jarak sliding maka semakin besar tinggi keausannya, dan semakin besar beban pada pin maka semakin besar tinggi keausan yang terjadi.

\section{KESIMPULAN}

Hasil pengujian point contact (pin-on-disc) bahan besi cor disc A (FCD 50) dan disc B (FCD 60) setelah dilakukan perlakuan permukaan electroplating hardchrome, maka dapat disimpulkan:

1. Karakter permukaan disc meningkat dari karakter awal. Ketebalan lapisan hardchrome disc 10,54 dan 12,8 $\mu \mathrm{m}$ membuat kekasaran disc meningkat hingga 3 kali $(382,3 \%)$ dari kekerasan awal.

2. Volume keausan terbesar terdapat pada disc B beban $20 \mathrm{~N}$ jarak $600 \mathrm{~m}$ yaitu sebesar $8,5387 \mathrm{~mm}^{3}$, dan volume keausan terkecil terdapat pada disc A beban $10 \mathrm{~N}$ jarak 200 meter yaitu sebesar $0,2083 \mathrm{~mm}^{3}$. Koefisien keausan terbesar terjadi pada disc $\mathrm{B}$ beban $20 \mathrm{~N}$ sebesar $7,1156 \times 10^{-7} \mathrm{~mm}^{3} / \mathrm{N} \cdot \mathrm{mm}$ dan koefisien keausan terendah terjadi pada disc A beban $10 \mathrm{~N}$ sebesar $1,48985 \times 10^{-7}$ $\mathrm{mm}^{3} / \mathrm{N} . \mathrm{mm}$. Tinggi keausan terbesar terdapat pada disc B beban $20 \mathrm{~N}$ jarak 600 $\mathrm{m}$ yaitu $0,071125222 \mathrm{~mm}$, dan tinggi keausan terkecil terdapat pada disc A beban $10 \mathrm{~N}$ jarak $200 \mathrm{~m}$ yaitu $0,004248622 \mathrm{~mm}$

\section{DAFTAR PUSTAKA}

Archard, J. F. (1953). Contact and Rubbing of Flat Surface. J. Appl. Phys , 24, 981-988.

Bayer, R. G. 2004. Mechanical Wear Foundrymentals and Testing Second Edition. Marcel Dekker, Inc. New York.

Bisa otomotif. Fungsi Ring Oli dan Ring Kompresi. www.bisaotomotif.com. Diakses 18 Juli 2019 jam 22.30.

Darmanto. Ridwan, M, T. Syafa'at, I. 2014. Analisis Keausan Alumunium Menggunakan Tribotester Pin-On-Disc Dengan Variasi Kondisi Pelumas. Vol. 10. Hal: 19-23.

Muchammad, Syafa'at, I., Helmi, F., Tauviqirrahman, M., Jamari. 2018. Wear Analysis of Spherical Graphite Cast Iron Using Pin-On-Disc Tribotester. Journal of Physical Science, Vol. 29, Hal: 15-26.
Setyahandana, B., Cristianto, Y. K. 2017. Pengaruh Hardchrome Plating Pada Peningkatan Kekerasan Baja Komponen Kincir. Media Teknika Jurnal Teknologi. Vol. 12, No. 1, Juni 2017.

Sugiharto, A. 2017. Analisa Keausan Disc FCB Dengan Alur Buatan Hasil Pembubutan Knurling DIN 82 melalui Pengujian Tribometer Pin-On-Disc Tanpa Pelumas. Tugas Akhir. Fakultas Teknik. Universitas Wahid Hasyim. Semarang.

Syafa'at, I. 2008. Tribologi, Daerah Pelumasan dan Keausan. Vol. 4. Hal: 21-26.

Zumgahr, Karl-Heinz. 1987. Microstructure and Wear of Materials Tribology Series 10th. Elsevier Institute of Materials Technology, University of Siegen. Siegen. Federal Republic of Germany. 